\title{
Influence of the presence of children taken care of in work motivation
}

\author{
Mariana Usheva, and Philip Ivanov* \\ South-West university "NeofitRilski", Faculty of economics, Department "Management and \\ marketing”, Ivan Mihailov 60, 2700 Blagoevgrad, Bulgaria
}

\begin{abstract}
Motivation is one of the most important aspects in human resources management. Motivated employees are often the difference between the good and great companies. The ever-complicating environment is demanding more and more from companies. In the current economical era, namely the human capital is the one thing, providing the requirements of the environment so that companies can afford to stay on the market. Therefore, everything linked to the proper human resources management should be examined in detail, which is the main purpose of the current study.

Here we aim to examine the link between the number of children for which the respondents are required to take care of and the most valuable motivators in workplace motivation. We firmly believe that the preferred motivators are directly linked to the number of children, with which we describe as the stage of the life cycle for each respondent.

First of all, in our article we would like to examine motivation as a part of the human resource management. Afterwards, we will examine the results from our survey, held among 595 respondents from various sectors of the Bulgarian economy. The survey was held in online format, guaranteeing the anonymity of the respondents. The larger part of the response group is part of a governmentally owned railway company.
\end{abstract}

\section{Introduction}

Examining motivation is one of the hardest tasks in human recourse management. Understanding what drives people to a certain behavior is maybe the most complex aspect of managing people, having in mind that motivation is directly linked to performance at work [9]. Motivation is one of the most important aspects in the company. Often, highly and properly motivated employees are the difference between the good and great companies.

This tendency is fully confirmed by the high interested among scholars. Numerous of authors have examined many aspects of motivation. From traits in the character of employees, to aspects from the environment. Our main goal in the current paper is to examine the link between the number of children, which have to be taken care of by our respondents and the most and least preferred motivators.

\footnotetext{
*Corresponding author: filip.ivanov.1@abv.bg
} 
In the first part of our paper we will examine the problem of motivation. We will give some examples of other proven linkages between traits in the character and environment and motivation to work. Then we will examine the results from our empirical research, and finally make conclusions based on the results.

\section{Materials and Methods}

In the this part we will examine the complexity of workplace motivation in many aspects. Firstly, we will try to explain the term motivation and motivating. Then we will examine some past research on the linkage between motivation and other aspects of everyday life and the workplace.

The word "motivation" has a Latin route from the word "movere", which means - to move. The problematic of motivation has been examined since the dawn of our civilization, beginning with the Greek-Roman Empire, where many of the philosophers examined the reason of certain action in people's behavior. The framework of motivation in everyday life is ever since in the focus of many philosophers and later of psychologists.

The concept of motivation refers to internal factors that impel action and to external factors that can act as inducements to action. The tree aspects of action that motivation can affect are direction (choice), intensity (effort), and duration (persistence) [6]. Therefore, workplace motivation is the main source of directed to the company success actions. Once the person is properly motivated, his efforts towards the required direction would be greater, the persistence will be more sustainable.

In the first place, motivation is no other than a phycological process, which initiates, directs and maintains goal-directed behavior. It is a process with which the individual steps into action [5]. It describes the most basic model for motivation. Firstly, the person acknowledges a certain desire, then he directs his behavior to the given action required in order to acquire that desire. The goal maintaining, which was described also as duration of the effort, is completely no other than a subjective process. The person is valuing the given incentive and estimates the effort he should put into acquiring it, then he steps into action with the according effort and persistence.

Consequently, motivation is a psychological process, which is routed from the interaction of the individual and the environment [9]. In the aspect of human resource management, the manager is the one who is responsible for the good, or respectively, bad motivational environment. Although it is very hard to put in practice many of the postulates of today's theorists examining the motivation in the workplace, managers are called to do whatever they could in providing suitable environment. The foundation for the good application is a good knowledge of the theories of motivation, many of the aspects of motivation as a psychological process in the human brain and last, but not least, what motivation is linked to as concerns other aspects of human behavior.

Of course, motivating of employees must be economically efficient for the organization. Companies can't give incentives for every effort they have to put, in order to maintain their work obligations. Widely used in the economy of the company is the Pareto's law. It states that $80 \%$ of the success for the firm comes from $20 \%$ of the employees. Although this law is widely used in many economical processes, motivating can partly reject it. Mostly because self-efficient behavior suggests certain effort for a given outcome for the employee, which basically means that the members of an organization typically do not bear all the costs and benefits of the actions they take and the decisions they make [11].

The last suggests a detailed examination of motivation as a whole and in the organization; it is of utmost importance to know what motivation relates to. Some examples are - national culture [12], age and adult development [13], equity on the workplace [1], goal setting [9], job characteristics [10], self-determination in behavior[4], personality traits 
(neuroticism, extraversion, openness to experience, agreeableness, conscientiousness) [3], feedback [2] and many other research-based traits of human behavior and aspects of the environment.

Although from the above-mentioned researches is shown that authors had examined the adult development in the aspect of human motivation, it was from another aspect, different from the aim in this article. The wide variety of research-based conclusions linked to the correlation of motivation and other aspects of human behavior and the environment, boldly emphasizes the importance of human motivation to theorists and practitioners in human resource management. Therefore, we believe that the current article will provide new knowledge in the theory of workplace motivation. Consequently, here comes the time to formulate our main hypothesis:

H1: The number of children to whom people have to take care of, is directly linked to the most valuable motivators in work.

We will examine the results of the empirical research in the bellow section of the article.

\section{Results and discussion}

The research was held in the form of an online survey in the period between June 2020 and August 2020. The bigger part of the response group is part of a governmentally owned railway company in Bulgaria $(n=448)$, the other part of the response group is from a wide variety of economic sectors in Bulgaria $(n=138)$, in total respondence $n .586$. We believe that the number of respondents is enough to let us make conclusions on the researched aspect of human motivation.

In order to examine the link between the number of children taken care from the respondents and the most valuable motivators in work, we divided the response group into 3 groups, respectively: no children taking care of; 1 child; 2 or more children.

In order to examine the workplace motivators, we gathered 38 examples from different theoretical authors and practice examples. The motivators were formulated into corresponding questions, using a 5-point Likert scale in order to examine the straight for each motivator subjectively for each respondent. Then we divided the motivators into 6 modules as follows: 1. Work Environment; 2. Remuneration; 3. Safety; 4. Personal development; 5. Affiliation and social aspects; 6. Respect and self-respect. Interest and challenge, autonomy and leadership.

We evaluated the most and least important motivators, by calculating the middle averages for each motivator and for the modules overall. On this foundation we examined the most and least preferred motivators, compared the results and made conclusions.

We will examine the results for each group respectively. Afterwards, we will compare the results from each group and examine the eventual differences and the results. The deviation for each group is as follows:

1. No children to take care of -240

2. 1 child to take care of -191

3. 2 or more children to take care of -155

It makes the No children group the largest and 2 or more children the smallest group in our research.

On Table 1 are shown the results from the group without children to take care of.

Table 1. No children to take care of, mean results

\begin{tabular}{|c|c|c|c|c|c|}
\hline Module 1 & Module 2 & Module 3 & Module 4 & Module 5 & Module 6 \\
\hline 3,798833 & 3,571357 & 3,715749 & 3,65728 & $\mathbf{3 , 9 1 9 2 6 7}$ & 3,671917 \\
\hline
\end{tabular}

Source: Own research 
As it is shown in the table, the least preferred module of motivators for the group of respondents without any children to take care of is Module 2 (Remuneration). Respectively, the most preferred module is Module 5 (Affiliation and social aspects).

Once it comes to examine motivators separately, the most preferred motivator for the current group is - "Comfortable working hours and brakes" part of Module 1 with a mean average of 4,137365. Correspondingly, the least preferred motivator for the examined group is - "Bonuses for diligence and results in work" part from Module 2 with a mean average of 3,175601 .

On Table 2 we look through the results for the group with 1 child to take care of.

Table 2. 1 child to take care of

\begin{tabular}{|c|c|c|c|c|c|}
\hline Module 1 & Module 2 & Module 3 & Module 4 & Module 5 & Module 6 \\
\hline 3,632161 & 3,250047 & 3,550136 & 3,460922 & $\mathbf{3 , 8 9 6 9 4 2}$ & 3,623743 \\
\hline
\end{tabular}

Source: Own research

In this group the tendency is basically the same, again Remuneration is the least preferred and Affiliation and social aspects is the most preferred module.

If we examine the motivators separately, here the most preferred is "Colleagues which are professionals", part of Module 5 and with an average of 4,085348. Respectively, the least preferred motivator is "Managerial responsibilities", part of Module 6, with an average of 2,932634.

And lastly, the results for the group with 2 or more children to take care of is shown in Table 3.

Table 3. 2 or more children to take care of

\begin{tabular}{|c|c|c|c|c|c|}
\hline Module 1 & Module 2 & Module 3 & Module 4 & Module 5 & Module 6 \\
\hline 3,527776 & 3,429019 & 3,579781 & 3,613155 & $\mathbf{3 , 8 4 2 0 0 9}$ & 3,634485 \\
\hline
\end{tabular}

Source: Own research

Again, the tendency is almost the same. Module 5 is the most preferred among respondence from the group, and Module 2 the least preferred module of motivators.

Divided, the most preferred motivators for this group is - "Comfortable working hours and brakes" part of Module 1 with a mean average of 4,096083. Respectively, the least preferred motivator is - "Various forms of financial incentives" part of Module 2 with a mean average of 3,157228 .

We will introduce the results from all 3 groups in Table 4, respectively, with most and least preferred modules.

Table 4 - Comparison between modules among groups

\begin{tabular}{|c|c|c|}
\hline No children & 1 child & 2 or more children \\
\hline Module $5-3,919267$ & Module $5-3,896942$ & Module 5 - 3,842009 \\
\hline Module $2-3,571357$ & Module 2 - 3,250047 & Module 2 - 3,429019 \\
\hline
\end{tabular}

Source: Own research

As we can see, as underlined already, the most preferred module is "Affiliation and social aspects", withthe highest average in the group without children to take care of. Respectively, the least preferred among the 3 groups is "Remuneration". 
By our opinion the most preferred among the 3 groups of respondents is namely, Module 2, because of the social nature of the human being. From the dawn of our evolutional development, people were tended to live in groups, take care of each other, observe social norms etc. Therefore, it is absolutely logical that we observe this preference in all 3 groups of respondents. People will always tend to make social non-formal groups on the work place. Although it is from upmost value to give such possibilities in the work environment, managers have to be careful, when using this motivator in practice.

The least preferred module for our response group is the one linked to financial and material incentives. Which partly proves that on the workplace people don't look for only material stimulation. Almost in every resent research in motivation it is proven that money and material incentives, are not the most preferred by the workers in almost every country in the world. Unfortunately, the theoretical research and practice are in big contradiction with each other. Even though, it is proven that remuneration is not the only and most appropriate insensitive it is the most applied in practice. Even more, some authors have proven that in certain conditions, pay is a negative motivator, and actually demotivates and lowers the results [14].

For more detailed examination of the differences among the respondents in the 3 groups, we will examine also the divided preferences among the motivators. The systematization is shown on Table 5 .

Table 5 . Comparison between motivators among groups

\begin{tabular}{|c|c|c|}
\hline No children & $\mathbf{1}$ child & $\mathbf{2}$ or more children \\
\hline $\begin{array}{c}\text { Comfortable working hours } \\
\text { and brakes }-\underline{4,137365}\end{array}$ & $\begin{array}{c}\text { Colleagues which are } \\
\text { professionals }-\underline{4,085348}\end{array}$ & $\begin{array}{c}\text { Comfortable working hours } \\
\text { and brakes }-\underline{4,096083}\end{array}$ \\
\hline $\begin{array}{c}\text { Bonuses for diligence and } \\
\text { results in work }-\underline{3,175601}\end{array}$ & $\begin{array}{c}\text { Managerial responsibilities - } \\
\text { Various forms of financial } \\
\text { incentives }-\underline{3,157228}\end{array}$ \\
\hline
\end{tabular}

Source: Own research

As we can see inTable 5, the most preferred among 2 groups (No children and 2 or more children) is the motivators "Comparable working hours and brakes". This may be a consequence of the necessity for more time with the family among the group with 2 or more children and the necessity for more free time among the group without children. Among the group with 1 child, the most preferred motivators are the professional colleagues, which is the first difference among the 3 groups. Therefore, this would be the first possible effect of the child presence in one's life.

We can see the tendency from examining the module preference also here. In 2 groups, the least preferred motivator is linked to remuneration. In the group with 1 child the least preferred motivator would be "Managerial responsibilities".

As we can see on Table 4 and Table 5, the tendency among the 3 examined groups is basically the same. Nevertheless, there is a small difference among the average attestation of the modules examined. There is also a small difference in the separate examination of the motivators.

This result cannot prove fully our hypothesis. Therefore, we cannot prove the direct and strong correlation of the presence of children in one's life and the most or least preferred motivators, having influence on worker's motivation. Nevertheless, there was a small difference among examined results. We observed difference in the average attestation for the modules in each group. Therefore, we are tended to say that there might me a small and weak correlation among the examined sign of human life and motivation to work. We examined a difference in the separately preferred motivators among the 3 groups, which 
partly confirmed the linkage between child presence and most and least preferred motivators.

\section{Conclusions}

In the current paper we examined the motivation at the work place. We underlined the importance of understanding motivation, once it comes to practically applying it. Managers have to examine motivation in their organizations, namely when there would be a proven correlation with some environment or individual trends.

Based on our results, we can cannot fully prove our hypothesis. Nonetheless, there were small differences in results among groups, which can partly prove a weak correlation between the examined variables.

We couldn't fully prove the correlation between the presence of children of one's life and work motivation, though. We are tended to say that managers have to be careful how they motivate people based on their life cycle as a whole and the number of their children. Although we haven't proven any direct link, other authors have proved such direct links.

Nonetheless, motivation will always remain one of the most important aspects in human management. Therefore, we need to have more detailed view on the theoretical work on many authors in the world and then we can formulate and apply motivational strategies. The necessity of theoretically based application of work motivation is mostly proved by the mismatch in using remuneration in motivating workers. In the current study we proved that remuneration is the least preferred among the modules. Herzberg has proved that pay is a hygienic factor in most kinds of jobs [7]. Rayan and Deci proved that pay can cause a negative effect on motivation and performance [15] [8]. Even though the mentioned authors have empirical prove for the mentioned tendency, practitioners are using more and more the pay for performance scheme in motivating employees. Such tendencies can be observed in many other aspects of human motivation, which we mentioned in the current paper.

Finally, although we could prove the direct link between the two examinate variables, we can conclude that motivation is one of the most complexed psychological trends in human resource management. Therefore, once it comes to motivation and examining motivation in a certain organization, the company needs to provide different forms of incentives among different kinds of workers, based on many trends, which we observed above.

\section{References}

1. S. Adams, New York: Academic press, 2, 267 (1965)

2. F. Belschak, D. Den Hartog, App. Psych.: An inter. Rev., 2, 274 (2009)

3. T. Bipp, Int.Jour.1 of Sel. and Assess.t, 1 (2010)

4. E. Deci, R. Ryan, Psych.l inq., 4, 227 (2000)

5. L. Deckers, Motivation: Biological, psychological, and environmental (2010)

6. Edwin A. Locke, Gary P. Latham, The Aca. of Manag. Rev., 3, 388 (2004)

7. F. Hercberg, Harv. Bus. Rev., 53 (1968)

8. C. Ilardi, K. Leone, T. Kasser, M. Rayan, Jour. of app. Soc. Psych.(1993)

9. G. Latham, C. Pinder, Ann.Psych.Rev., 485 (2005)

10. G. Oldham, J. Hackman, Admini.Sci. quart., 1, 66 (1981)

11. G. Robert, John Roberts, Princeton University Press, 56 (2012)

12. R. Robert, Irina Zinovieva, E. Dienes, App. Psych.: an intern. Rev., 4, 658 (2000) 
13. R. Kanfer, P. Ackerman, The Ac. of Manag. Rev., 3, 440 (2004)

14. R. Ryan, E. Deci, Journ.of Person., 74, December, 1557 (2006)

15. M. Zuckerman, J. Porac, D. Lathin, R. Smith, L. Deci, Person. and Soc.Psych. bull, 4 (1978) 